\title{
DIAGNÓTICO SÓCIO-ECONÔMICO E CULTURAL NAS COMUNIDADES PESQUEIRAS ARTESANAIS DO LITORAL CENTRO-NORTE DO ESTADO DE SANTA CATARINA
}

\author{
MEDEIROS, R.P.; POLETTE, M.; VIZINHO, S.C.; MACEDO, C.X. \& J. C. BORGES
}

Universidade do Vale do Itajaí - Faculdade de Ciências do Mar.

\begin{abstract}
RESUMO
A pesca artesanal é uma atividade tradicional na Zona Costeira do Estado de Santa Catarina, exercendo um importante papel histórico, social e econômico nesta região. Este estudo foi realizado no litoral Centro-Norte do Estado de Santa Catarina, incluindo 10 municípios: Barra Velha, Piçarras, Penha, Navegantes, Itajaí, Balneário Camboriú, Itapema, Porto Belo, Bombinhas e Tijucas, onde um diagnóstico e planejamento ambiental foi produzido. Para realizar este diagnóstico, foram realizadas 482 entrevistas com pescadores artesanais. Os resultados indicaram que a pesca de arrasto de camarão é a principal atividade pesqueira artesanal da área. Verificou-se também que, em geral, a pesca artesanal apresenta problemas importantes como a falta de fiscalização da atuação da frota industrial próxima à costa e a falta de uma política de apoio à pesca artesanal. Um outro sério problema é o desenvolvimento desordenado da orla marítima, antiาgamente dominada por comunidades pesqueiras. Isto resultou numa diminuição do número de pescadores na comunidade e uma diminuição da rentabilidade da pesca. Soluções imediatas, como por exemplo, programas de extensão universitária, educação ambiental e uma reavaliação da política pesqueira devem ser realizadas antes que esta atividade desapareça do litoral Centro-Norte do Estado de Santa Catarina.
\end{abstract}

Palavras Chave: Pesca Artesanal, Santa Catarina, Diagnóstico Sócio-econômico e Cultural, Comunidades Pesqueiras.

\section{SOCIAL, ECONOMIC AND CULTURAL DIAGNOSIS OF THE ARTISANAL FISHERMEN COMMUNITIES OF THE CENTER-NORTH SANTA CATARINA COASTAL ZONE.}

\begin{abstract}
The artisanal fishery is a traditional activity in the coastal Zone of Santa Catarina State, playing an important historical-social and economic role in this region. This study was conducted in the central and Northern part of Santa Catarina coastal zone, which included ten municipalities: Barra Velha, Piçarras, Penha, Navegantes, Itajaí, Balneário Camboriú, Itapema, Porto Belo, Bombinhas and Tijucas. A diagnosis of artisanal fishery in this area was achieved through 482 questionnairy interviews with fishermen and their families. The results indicated that artisanal shrimp fishery is the main activity in this area. It was also verified that the artisanal fisheries as a whole has serious problems such as the lack of fiscalization of the industrial fleet near the coastline, and 'he lack of supporting policies for these fishery sector. Another serious problem is the non planned urbanisation in the beaches formely dominated by fishermen settlement. As a result, it was verified a decrease of the number of fishermen and a decrease in the economical benefits of the artisanal fishing activity. Immediate solutions, such as universitary extension programs such as environmental education and revaluation of the fishery policies must be taken before this culturally and historically important activity disappears from Center North Santa Catarina coastal zone.
\end{abstract}

Key-words: Artisanal Fishery, Santa Catarina, Social Economic and Cultural Diagnosis, Fishermen Communities. 


\section{INTRODUÇÃO}

Atualmente as comunidades pesqueiras vem sofrendo diversos impactos, que colocam em risco o seu destino para o futuro. A presença da frota pesqueira industrial operando próxima a costa, fora dos seus limites mínimos para realizar a pesca, vem causando uma competição desigual com as embarcações artesanais na disputa pelo pescado costeiro (Lima, 1994; Martins, 1988 e Gaplan, 1986).

O crescimento desordenado do turismo, também vem causando sérios problemas às comunidades pesqueiras artesanais, promovendo uma disputa pelo espaço costeiro, onde muitas moradias de famílias de pescadores e ranchos de embarcações dão lugar a edifícios, restaurantes, e outras edificações.

Baseado nestes argumentos este trabalho teve por objetivo realizar um diagnóstico sócio-econômico e cultural de comunidades pesqueiras artesanais localizadas no litoral Centro-Norte Catarinense, buscando identificar seus principais problemas, bem como verificar a sua evolução e estruturação ao longo do tempo e espaço, para que seja possível realizar futuros trabalhos adequados de Planejamento Costeiro na área.

\section{AREA DE ESTUDO E METODOLOGIA}

Os dados foram obtidos através de 482 entrevistas com pescadores e mulheres de pescadores entre os meses de setembro de 1994 e junho de 1995. As entrevistas foram realizadas com um roteiro que passou por uma fase de testes, através de amostragens-piloto, durante um período de três meses (junho à agosto de 1994). Os pescadores foram entrevistados na beira da praia, ranchos de pesca, peixarias, bares típicos e, em alguns casos, nas próprias residências dos pescadores.

A tabela 1 mostra as comunidades pesqueiras artesanais identificadas (em. suasrespectivas Colônias de Pescadores) e a quantidade de pescadores entrevistados em cada uma delas. Em virtude da falta de registros atualizados no número de pescadores em cada Colônia de Pescadores, que ainda praticam a profissão, fica a incerteza da significância do número de pescadores entrevistados em relação ao número total de pescadores em atividade em cada comunidade. Para tentar reduzir esta margem de erro, os próprios pescadores foram questionados quanto ao número aproximado de pescadores em atividade em cada comunidade.

$O$ estudo foi realizado numa faixa de 171 quilômetros de linha costa (fig. 1), limi-tada ao Norte pela foz do Rio Itapocu (divisa entre os municípios de Barra Velha e Araquari), e ao Sul pela foz do Rio Tijucas (município de Tijucas). Dentro destes limites encontram-se os municípios de Barra Velha, Piçarras, Penha, Navegantes, Itajaí, Balneário Cannboriú, Itapema, Porto Belo,

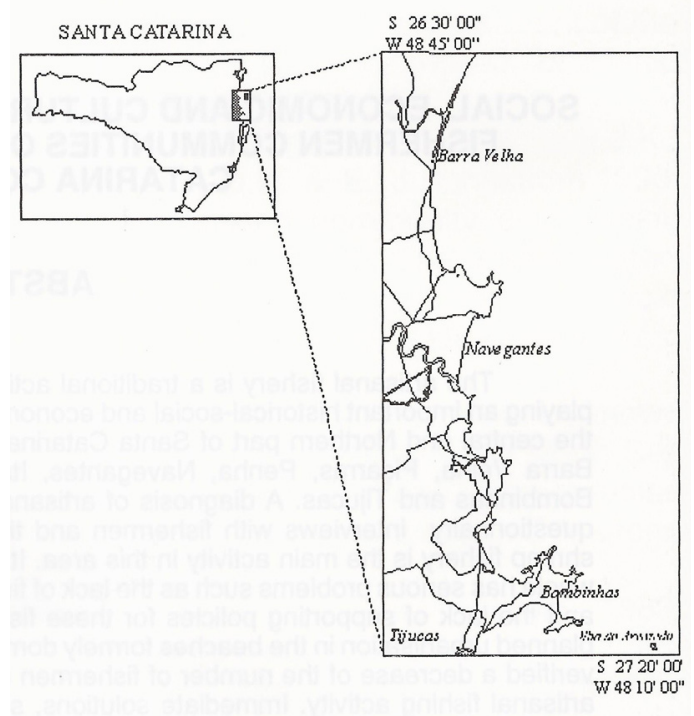

Figura 1 - Localização do litoral Centro-Norte Catarinense. 
Bombinhas e Tijucas, nos quais foram identificados 18 comunidades distribuídas ao longo de 7 Zonas de Pesca (tabela 1).

\section{RESULTADOS E DISCUSSÃO}

Os resultados a seguir são apresentados em porcentagem do total de respostas dadas pelos pescadores entrevistados no litoral Centro-Norte do Estado de Santa Catarina (482).

\section{Perfil dos pescadores}

Famílias de pescadores encontramse espalhadas por quase todo o litoral Centro-Norte Catarinense, mas as maiores concentrações de pescadores situam-se nas diversas enseadas, baías e margens dos estuários que este trecho do litoral oferece, proporcionando abrigo e facilitando a saída e entrada das embarcações. A maioria dos pescadores $(77,13 \%)$ começou a pescar com seus pais e avós, seguindo a tradição da família. O restante $(22,87 \%)$ não tem tradição familiar na pesca, e a maioria destes veio de outra cidade (do interior) onde realizava outra atividade. A maior parte dos entrevistados são associados às Colônias de Pescadores próximas à sua comunidade, representando $76,35 \%$ dos pescadores entrevistados. O restante $(23,65 \%)$, alega não ser associado à colônia devido ao seu descrédito com a mesma, por considerá-la não beneficente aos pescadores.

A pesca artesanal no litoral CentroNorte Catarinense é principalmente representada pelos pescadores com idade entre 31 e 50 anos (Fig. 2). Praticamente todos os pescadores entrevistados com idades inferiores. a 31 anos realizavam paralelamente a pesca industrial, sendo que esta última representa a maior parte da renda mensal. Atribui-se o baixo número de pescadores com idade inferior a 20 anos ao fato de que estes, que são filhos de pescadores, ainda estão estudando ou estão seguindo uma profissão diferente da pesca. Quando atuam na pesca, a maioria dedica-se a pesca industrial.

Tabela 1 - Comunidades pesqueiras artesanais do litoral Centro-Norte Catarinense. A sequência é apresntada sob a orientação Norte-Sul.

\begin{tabular}{|c|c|c|c|}
\hline finnat de pesca & Municípios & Comunidades de pesca & $N$ \\
\hline \multirow[t]{2}{*}{$X a 1$} & Barra Velha & Praia da Canoa & 59 \\
\hline & & Praia de Itajuba & 22 \\
\hline \multirow{3}{*}{25} & Piçarras & Piçarras & 17 \\
\hline & Penha & Armação da Penha & 57 \\
\hline & & São Miguel & 18 \\
\hline \multirow[t]{2}{*}{20} & Navegantes & Gravatá & 17 \\
\hline & & Pontal & 40 \\
\hline 8.7 & Balneário Camboriú & Barra do Rio Camboriú & 56 \\
\hline \multirow[t]{2}{*}{10} & Itapema & Canto da Praia & 20 \\
\hline & & Perequê & 9 \\
\hline \multirow[t]{4}{*}{211} & Porto Belo & Porto Belo & 16 \\
\hline & & Araçá & 33 \\
\hline & & Santa Luzia & 36 \\
\hline & Tijucas & Barra do Rio Tijucas & 6 \\
\hline \multirow[t]{4}{*}{2,43} & Bombinhas & Quatro Ilhas & 3 \\
\hline & & Bombinhas & 3 \\
\hline & & Zimbros & 32 \\
\hline & & Canto Grande & 38 \\
\hline HOTAI & & & 482 \\
\hline
\end{tabular}


A maior parte dos pescadores (56\%) estudou até o primário, sendo que a $4^{\text {a. }}$ série foi cursada por $28,57 \%$ do total de pescadores entrevistados. Além destes, $28,4 \%$ dos pescadores estudaram até a 8 a série (representado basicamente pelos pescadores com idade até 30 anos), 2,6\% estudaram até o $2^{\circ}$. grau e $2,0 \%$ iniciaram a faculdade sem concluir. Os restantes, $11 \%$, não possuem instrução escolar e são anal-fabetos. Apesar de que a maior parte dos pescadores tem uma certa escolaridade, na prática, a maioria dos pescadores são analfabetos devido ao tempo que os mesmos estão sem estudar.

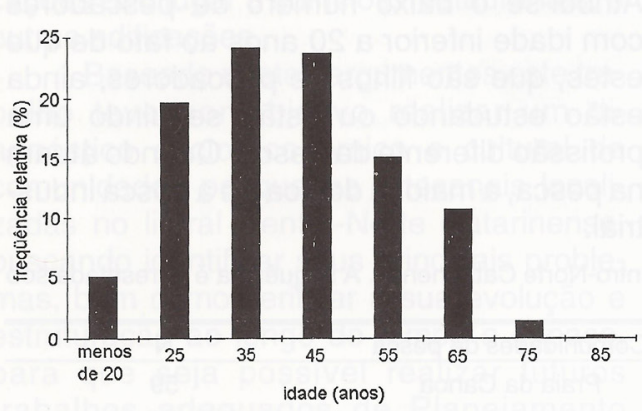

Figura 2 - Distribuição de freqüência relativa da idade dos pescadores artesanais do litoral Centro-Norte Catarinense.

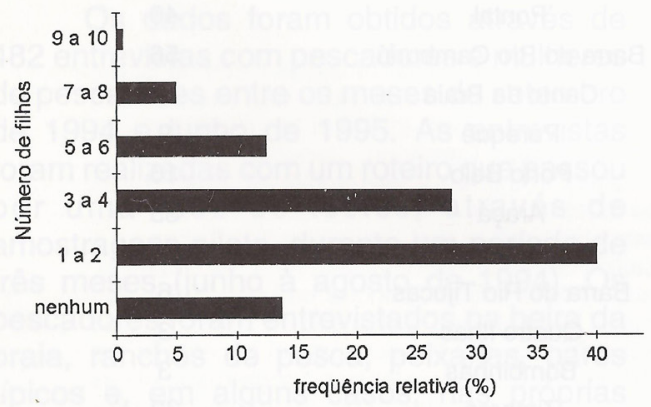

Figura 3 - Freqüência do número de filhos em cada família de pescador, nas comunidades pesqueiras artesanais do Litoral Centro- Norte Catarinense.
A maior parte das famílias de pescadores é compostas de três a quatro pessoas, tendo um a dois filhos por família (Fig. 3). A maioria desses filhos não seguem a profissão do pai, principalmente porque seus pais não querem seus filhos seguindo a profissão de pescador (Fig. 4 e Fig. 5). A situação pela qual passa a pesca artesanal atualmente faz com que a maioria dos pescadores artesanais aleguem principalmente que a pesca é uma atividade muito sofrida e muito perigosa. Já os pescadores que gostariam que o filho fosse também pescador, querem que a tradição da família seja mantida (56,72\% das respostas).

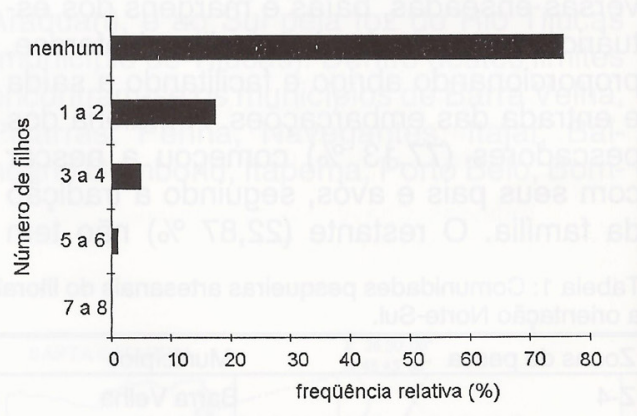

Figura 4 - Freqüência do número de filhos pescadores em cada família de pescador no litoral Centro-Norte Catarinense.

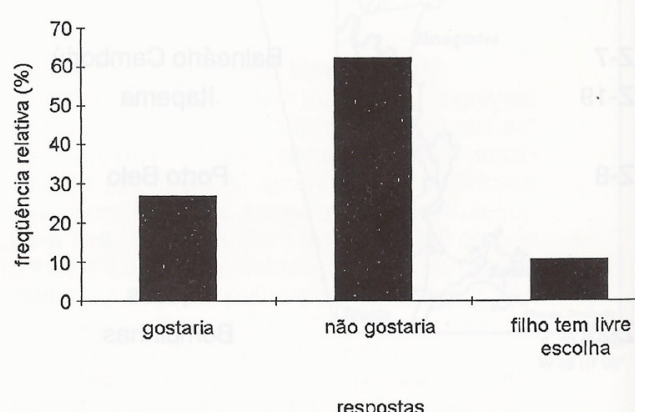

Figura 5 - Distribuição percentual das respostas para a pergunta: "O senhor gostaria que o seu filho fosse pescador?". 


\section{A pesca no litoral Centro-Norte Catarinense}

A maior parte dos pescadores pesca com embarcações (49,47\%), sendo menos freqüentes as atividades de arrasto de praia, pesca de linha no costão e outras atividades. Dos pescadores entrevistados, 51,8 \% não são proprietários de embarcações e realizam pesca em parceria, geralmente com o pai ou o irmão (principalmente na pesca com redes de emalhe). Os pescadores proprietários de embarcações geralmente pescam camarão sozinhos, pescaria que envolve, na maioria dos casos, apenas um pescador na embarcação. As principais embarcações utilizadas nas comunidades são a baleeira, o bote, a bateira e a canoa, com comprimentos variando entre 7,5 metros e 10 metros. Os pescadores não foram questionados a respeito da potência do motor.

A pesca artesanal no Litoral CentroNorte Catarinense, bem como em todo litoral Catarinense (Branco \& Rebelo, 1994), apresenta uma grande variedade tanto de apetrechos de pesca como de espécies capturadas. O principal apetrecho de pesca utilizado é a rede dupla de arrasto de fundo, utilizada na pesca artesanal do camarão.

Além da rede de arrasto de fundo (ou rede de portas), são utilizadas também as redes de emalhar de fundo (rede de espera) e de caceio. As redes de emalhe ou redes de espera, segundo Branco \& Rebelo (1994), são as artes de pesca mais representativas, a nível de produção controlada, representando cerca de $33 \%$ captura total de peixes no ano de 1993 no Estado de Santa Catarina. Redes de Cerco também são utilizadas na pesca de peixes pelágicos como as espécies de tainha (Mugil spp), segundo os pescadores entrevistados. Descrições mais detalhadas das artes de pesca artesanal são descritas em Marques (1980).

De acordo com as entrevistas, a maior parte dos pescadores do litoral praticam a pesca do camarão, tanto no verão (32,49\%), como no inverno $(24,40 \%)$. Os pescadores adotam a estação de inverno equivalente aos meses de maio a outubro, enquanto que o verão corresponde aos meses de novembro a abril. Vale ressaltar que esta denominação não está relacionada a uma falta de conhecimento às quatro estações do ano, e sim a safras de pescaria, onde existem os peixes de inverno, por exemplo espécies de linguado (Bothidae) e os peixes de verão, como exemplo as espécies de robalo (Centropomus spp), segundo os pescadores entrevistados. Além do camarão, os pescadores entrevistados responderam que os peixes mais capturados são: os cações (principalmente Sphyrnidae) $(15,69 \%)$ e garoupas (Serranidae) $(7,0 \%)$ no verão, a corvina (Micropogonias fumien) $(17,63 \%)$ e a tainha (Mugil spp) $(15,94 \%)$ no inverno. Diversos outros peixes são capturados, mas estes foram os mais representativos de acordo com a opinião dos pescadores artesanais.

As ilhas têm grande importância para os pescadores, já que servem de ponto de referência para localização das áreas de pesca e ainda constituem a própria área de pesca (pesqueiro, segundo os pescadores) para a pesca de peixes como a garoupa (Serranidae) e o badejo (Serranidae). A pesca da lula também tem grande importância, principalmente nas llhas que compreendem a Reserva Biológica Marinha do Arvoredo (Fig. 6) (Perez et al., neste volume). Alguns pescadores também realizam a coleta de marisco nas ilhas próximas a sua comunidade.

A pesca da tainha movimenta praticamente todas as comunidades pesqueiras visitadas, durante os meses de maio a julho. Muitos pescadores ficam em terra a espera dos cardumes, que chegam bem próximos à praia.

Segundo os pescadores, os cinco pescados de maior importância econômica (porcentagem do total de respostas) são:

Verão: Camarão (24,44 \%); Garoupa (20,28\%); Cação (15\%); Pescada (Sciaenidae) $(14,44 \%)$ e o Robalo (Centropomus spp) (5\%); 
Inverno: Camarão (21,73 \%); Tainha $(18,75 \%)$; Pescada (Sciaenidae) $(15,18 \%)$; Corvina $(12,8 \%)$ e a Anchova (Pomatomus saltator) $(5,95 \%)$.

Nas comunidades onde o desembarque é realizado na beira da praia o peixe é vendido para os moradores e turistas, principalmente no verão. Já durante o inverno a maior parte do pescado é vendido para peixarias e firmas de pesca. Comunidades que não recebem turistas (e.g., Santa Luzia e de Pontal) vendem o pescado para o intermediário durante $\mathrm{o}$ ano todo.

Cerca de metade dos pescadores artesanais entrevistados viviam exclusivamente da pesca, representando $55 \%$ dos pescadores entrevistados. O restante, realizava atividades ligadas ao comércio, passeios de barco com turistas, de caseiro no verão e ainda, de serventes de construção, pintor e outras que não exigem escolaridade, como profissão alternativa. A alta exigência de mão de obra para o desen-volvimento do turismo tem levado muitospescadores a deixar sua atividade original para trabalhar em atividades turísticas.

O cultivo de mexilhões (Perna perna) era realizado por $4,5 \%$ dos pescadores entrevistados como fonte de renda alternativa, durante o período de amostragens. O cultivo desse e outros moluscos (ostras e mariscos) vem aumentando nas comunidades de pesca, permitindo com que aumente o número de pescadores que tenha uma fonte adicional à pesca. Segundo dados da EPAGRI (1996), os municípios de Bombinhas (comunidades de Canto Grande e Zimbros) e Penha (comunidade de Armação da Penha) obtiveram respectivamente a terceira e a quarta maior produção de mexilhões do Estado de Santa Catarina no ano de 1995.

Pode-se então verificar que esta atividade vem assumindo uma posição de destaque no contexto sócio-econômico da pesca artesanal do litoral Centro-Norte Catarinense, o que, por outro lado, pode

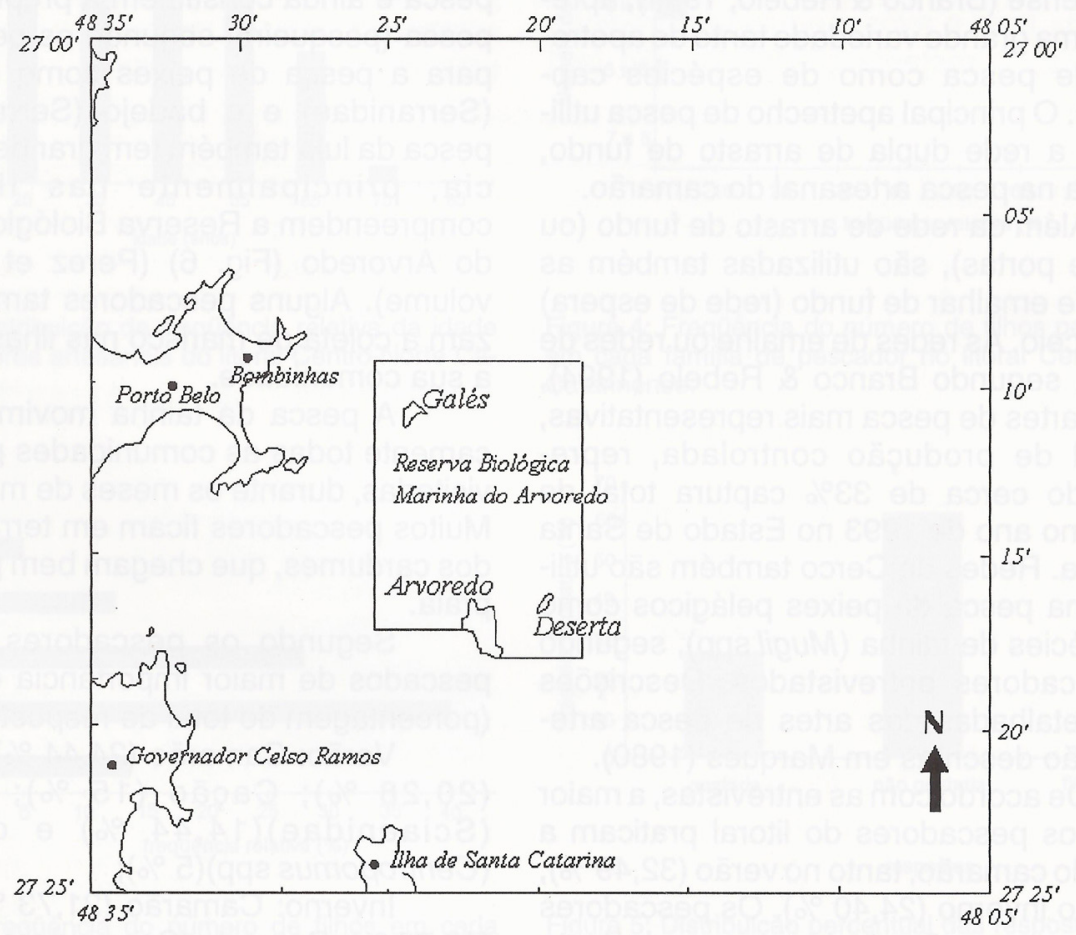

Figura 6 - Reserva Biológica Marinha do Arvoredo e área de entorno. 
acarretar no enfraquecimento das comunidades pesqueiras, uma vez que é verificado um êxodo da pesca. Isto significa que alguns pescadores estão deixando de valorizar a sua profissão tradicional para seguir a profissão de maricultor.

Até o momento foram criadas duas associações de maricultores na área de estudo. Uma na Comunidade de Canto Grande e a outra na Comunidade de Praia de Armação, que recebe a orientação de oceanógrafos do corpo docente/pesquisa da Faculdade de Ciências do Mar (UNIVALI/FACIMAR), especialistas em maricultura.

\section{Situação da pesca artesanal}

A pesca artesanal no litoral CentroNorte Catarinense vem sofrendo diversos impactos ao longo de sua existência, segundo depoimentos informais de pescadores, principalmente aqueles que já abandonaram a profissão e estão acompanhando seus filhos seguirem a tradição:

\section{Falta de fiscalização da atuação das embarcações industriais, provenientes de Itajaí:}

A legislação a respeito da área de atuação da frota pesqueira industrial é bastante confusa, mas segundo os pescadores entrevistados os barcos industriais têm um limite mínimo (1 milha) de distância do ponto mais afastado da costa para realizar sua atividade, que muitas vezes não é respeitado. Algumas embarcações se aproximam da costa, a procura de isca viva, utilizada na pesca do bonito. Esta isca viva compõe-se de juvenis em crescimento de sardinhas (Clupeidae) e engraulídeos nas águas mais rasas, chamados pelo pescador de manjuba (Wongtschwski et ai, 1995; Lins, 1992). Os pescadores entrevistados responderam que a isca-viva é o alimento dos peixes que são de interesse econômico para a pesca artesanal, revelando uma noção de cadeia trófica. Eles consideram que acabando com o alimento, os seus recursos terão a tendência de se esgotarem.

Também são realizadas as pescas cerco e de arrasto de fundo de porta e de parelha (dois barcos juntos puxam uma rede de arrasto). Isto gera uma competição desigual entre as embarcações industriais e as embarcações artesanais. Além disso, muitas redes de pescadores artesanais são "atropeladas" por estes barcos cerqueiros e arrasteiros, quando estes estes atingem as áreas mais costeiras

Ausência de uma política de apoio à pesca: Os pescadores entrevistados criticam a falta de um programa de incentivos à pesca artesanal.

Falta de cooperativas de pesca: Esta instituição permitiria que o pescador pesque e ele mesmo venda, acabando assim com a ação do atravessador dentro das comunidades.

Diminuição gradativa das capturas ao longo dos anos: Muitos pescadores consideram que o produto da pesca vem se tornado cada vez mais reduzido. O grande aumento do esforço vem causando uma diminuição do estoque de camarão, como fcú observado pelo Grupo Permanente de Estudos de Camarões (1993), reafirmando o depoimento dos pescadores. O mesmo pode ser observado na pesca de peixes demersais, segundo o Grupo Permanente de Estudos sobre Peixes demersais (1993), onde os níveis altos de esforço são os principais responsáveis pela diminuição da produção pesqueira anual.

Os problemas apontados neste trabalho, baseado nas entrevistas com os pescadores artesanais, são comuns em diversas comunidades do litoral catarinense e, de uma forma geral, no litoral brasileiro (Stride, 1992; Kremer, 1990; Antunes, 1986; Mello, 1985; Paturce, 1975; Rothschild, 1975; Lago, 1961). Comparando as referências lidas com os resultados obtidos, parece que a problemática vem ocorrendo nos últimos 40 anos, mostrando uma tendência de agravamento para os próximos anos. 


\section{PROBLEMAS, RECOMENDAÇÕES E ANÁLISE CRÍTICA DOS DADOS}

A pesca artesanal no litoral CentroNorte Catarinense é exercida principalmente pelos pescadores mais velhos da comunidade (faixa etária entre 31 e 50 anos). Os pescadores mais novos estão mais dedicados a pesca industrial. Além disso, os filhos de pescadores têm optado por estudar mais e tentar uma profissão diferente da pesca. Pode-se dizer que vem ocorrendo uma certa "falha no recrutamento" nas comunidades pesqueiras. Isto pode acarretar numa perda de espaço no tocante da utilização dos recursos marinhos.

A maior parte dos pescadores artesanais não querem que seus filhos sigam a tradição da pesca. Eles parecem alegar problemas muito mais relacionados à desvalorização sócio-cultural do que econômica, uma vez que os pescadores percebem um certo descaso das autoridades competentes. A tendência de diminuição do número de fiIhos pescadores que seguem esta profissão tradicional, observada neste trabalho, apesar da ausência de um acompanhamento temporal das comunidades e ser baseado apenas em entrevistas, pode ser verificada principalmente nas classes etárias que atuam na pesca. As bibliografias lidas também enfatizam a suposição de declínio da pesca artesanal feita neste trabalho.

O sistema de fiscalização aplicado à pesca é muito precário. A falta de subsídios científicos para um melhor conhecimento das comunidades pode ser um dos fatores que vêm enfatizando o descaso das autoridades competentes. Algumas comunidades que estão localizadas no litoral Centro-Norte Catarinense nem têm seus desembarques controlados pelo IBAMA, como foi descrito por Branco \& Rebei,, (1994). Desta forma, a falta de conhecimento da situação das comunidades dificulta consideravelmente qualquer programa de manejo.

O processo de melhoria na pesca ar- tesanal não depende somente de órgãos de pesquisa e das instituições responsáveispelo setor. Deve-se também ser bastante crítico quanto à disposição do próprio pescador em melhorar sua situação. Existe uma certa falta de organização nas comunidades e os pescadores demonstra-se desmotivado (mesmo causado pela falta de incentivos do governo) para exigir seus próprios direitos. É importante que os pescadores artesanais se unam em suas comunidades para que esta fique mais fortalecida social, econômica e politicamente, procurando e informar a respeito de seus direitos e deveres.

O desenvolvimento desordenado do turismo também vem contribuindo para a descaracterização das comunidades litorâneas. A falta de um planejamento adequado para o turismo vem causando problemas de organização do espaço nas praias, onde a maioria das comunidades estão situadas. A especulação imobiliária na orla marítima vem causando a expulsão do pescador da beira da praia, bem como seus ranchos e embarcações, para pontos mais afastados, dificultando a sua situação. Os trabalhos de Planejamento, com subsídios científicos sobre a ecologia, sociologia e a economia da região podem ser aplicados para tentar controlar o desenvolvimento desordenado que hoje ocorre nas praias do litoral CentroNorte catarinense.

A Reserva Biológica Marinha do Arvoredo é motivo de conflitos entre órgãos fiscalizadores (IBAMA) e pescadores artesanais. Parece que as fiscalizações são mais rígidas sobre esta classe política e socialmente mais frágil, em relação a outros grupos que usufruem da reserva, como operadoras de mergulho e a frota pesqueira industrial. Esta Unidade de Conservação foi estabelecida sem que fossem levados em consideração a importância histórica, cultural, social e econômica da das comunidades adjacentes (Fig. 6). Sugere-se que sejam realizados estudos procurando reavaliar a situação atual da reserva, buscando um manejo mais 
adequado para esta região.

A maior parte dos pescadores artesanais vive exclusivamente da pesca artesanal. As atividades de maricultura podem surgir como uma importante fonte de renda alternativa. Por outro lado, o cultivo de mexilhões também pode causar um certo enfraquecimento das comunidades pesqueiras, pois esta atividade pode ser mais uma via de saída de pescadores de sua atividade tradicional.

Existe uma tendência de declínio da pesca artesanal no litoral Centro-Norte Catarinense que são evidenciadas a partir dos resultados obtidos. Sugere-se que sejam criados programas de apoio e extensão universitária visando a criação de programas de assistência médica e odontológica, jurídica e educacional, bem como programas de educação ambiental, buscando mostrar às famílias de pescadores uma melhor forma de conviver com o meio ambiente.

Este trabalho permitiu uma melhor compreensão da situação atual das comunidades pesqueiras do litoral Centro-Norte Catarinense. Vale ressaltar que todos os comentários foram baseados nas 482 entrevistas realizadas com os pescadores, procurando-se utilizar uma linguagem mais fiel possível com o depoimento dos pescadores. Seria importante que este mesmo trabalho fosse realizado nas demais comunidades do litoral catarinense, bem como de todo o litoral brasileiro, pois ele permite que sejam definidos os nichos ou papéis de cada membro da comunidade na sustentabilidade destas, cabendo às instituições governamentais e de pesquisa demonstrarem a importância social, histórica e cultural desta atividade no contexto dos municípios litorâneos.

\section{AGRADECIMENTOS}

Gostariamos de agradecer ao Conselho Nacional de Desenvolvimento Científico e Tecnológico (CNPq) pelo fornecimento da bolsa de Iniciação Científica e à Fundação
Banco do Brasil pelo financiamento do projeto. Gostaria também de agradecer a José Angel Perez e Humber Agreli Andrade, pelos conselhos dados embusca de um melhor desenvolvimento do trabalho. Finalmente, gostaria de agradecer aos pescadores artesanais do litoral Centro-Norte Catarinense, pois sem a colaboração destes este trabalho não seria possível.

\section{REFERÊNCIAS BIBLIOGRÁFICAS}

Antunes, M.0.. 1985. Aspectos sócioeconômico-culturais do distrito de ribeirão da ilha. Dissertação de monografia, Universidade Federal de Santa Catarina. Florianópolis, SC.

Branco, E.J. \& S. Rebelo. 1994. Desembarques controlados de pescados: Estado de Santa Catarina - 1993. 1BAMA/ CEPSUL. Coleção Meio Ambiente: Série EstudosPesca, n. 14. Itajaí. 133p.

EPAGRI. 1996. Produção de mexilhões no Estado de Santa Catarina - 1995. Relatório não publicado.

Gaplan/SC. 1986. Atlas de Santa Catarina. Aerofoto Cruzeiro, Rio de Janeiro. 173 p. GPE. 1993. Camarões do sudeste e sul. Coleção Meio Ambiente: Série EstudosPesca, n. 5. IBAMA/CEPSUL. 68 p.

GPE. 1993. Peixes demersais. Coleção Meio Ambiente: Série Estudos - Pesca, n. 8. IBAMA/CEPSUL. 93 p.

Kremer, M.C. 1990. A pesca na Barra da Lagoa. Dissertação (bacharelado em Geografia) - Centro de Filosofia e Ciências Humanas, Departamento de Geociências, Universidade Federal de Santa Catarina. Florianópolis, SC.

Lago, P.F.A. 1961. Contribuição geográfica ao estudo da pesca em Santa Catarina. Revista Brasileira de Geografia, n.1, jan/mar. IBGE-Conselho Nacional de Geografia. Rio de Janeiro, RJ.

Lima, D. 1994. Pesca artesanal: problemas econômicos e sociais dos pescadores 
artesanais da localidade de SambaquiFlorianópolis. Dissertação (bacharelado em Geografia)-Centro de Filosofia e Ciências Humanas, Universidade Federal de Santa Catarina. Florianópolis, SC.

Lins, C.F. 1992. Atuns e afins: estimativa da quantidade de isca viva utilizada pela frota atuneira. IBAMA. Secretaria do Meio Ambiente. Coleção Meio Ambiente: Série Estudos-Pesca. n. 6. Brasília. DF.

Marques, L.A.B. 1980.0 pescador artesanal do sul. Prêmio Sílvio Romero - 1973. MEC-SEAC-FUNARTE. Instituto Nacional do Folclore. Rio de Janeiro, RJ.

Martins, N.N. 1988. O declínio da pesca artesanal na baía sul de Florianópolis a partir da década de 50. Dissertação (bacharelado em Geografia) - Centro de Filosofia e Ciências Humanas, Universidade Federal de Santa Catarina. Florianópolis, SC.

Mello, A.F. 1985. A pesca sob o capital: a tecnologia a serviço da dominação. Universidade Federal do Pará. Belém. PA.
Paturce, G. 1975. Pesca, peixes e pescarias. Ed. Italiana. Belo Horizonte, MG.

Perez, J.A.A; Schettini, C.A.; Buratto, J.R. \& M. J. Machado. (neste volume). A pesca de lulas (Mollusca: Cephalopoda) na Ilha do Arvoredo (SC): características e relações ecológicas - Verão de 1996. Notas Técnicas da FACIMAR. 1: 9-21.

Rothschild, B.J. 1975. A pesca: seus recursos e interesses nacionais. Ibrasa : São Paulo.

Stride, R.K. 1992. Diagnóstico da pesca artesanal marinha do Estado do Maranhão. (Projeto Desenvolvimento da Pesca Artesanal Marinha do Maranhão) CORSUP-Universidade Federal do Maranhão. Ed. Universitária. São Luis, MA.

Wongtschowski, C.R.; Saccardo, S.A. \& M. C. Cergole. 1995. Situação do estoque da sardinha (Sardinella brasiliensis) no litoral sudeste e sul do Brasil. Coleção meio Ambiente: Série estudos - Pesca, $n$. 17. IBAMA/CEPSUL. Itajaí. $50 \mathrm{p}$. 